\title{
An Opinion On Independent Auditors Opinions Of Substantial Doubt: A SOX-2002 Efficiency Evaluation
}

Jeff Grover, (Email: jeff.grover@indwes.edu), Indiana Wesleyan University Angeline M. Lavin, (Email: alavin@usd.edu), University of South Dakota

\begin{abstract}
Given the recent events involving allegations of ethical misconduct by corporate executives and oversight neglect from the auditing community, the government was motivated to implement national reform to minimize the continued threat of corporate malfeasance. Due to the severity of these corporate scandals, Congress mandated and the President signed into law the Sarbanes-Oxley Act of 2002 (SOX-2002) to affect sweeping corporate disclosure and financial reporting reform to thwart continued scrupulous activities. In light of these events, the motivation of this study is to examine the effects of SOX-2002 in empowering independent auditors to provide unbiased opinions of an entity's ability to remain as a going concern. The uniqueness of this study is that it attempts to determine if substantial doubt opinions signal bankruptcy greater than the chance occurrence of these events. If true, then these early warnings could be used to minimize the costs of bankruptcy. This study suggests that these opinions do signal bankruptcy filings greater than chance, which supports the position of auditor empowerment in a post-SOX-2002 period.
\end{abstract}

\section{INTRODUCTION}

$\mathrm{n}$ the wake of several recent, highly publicized corporate bankruptcies, investors and regulators alike have wondered why the risk of these companies was virtually unidentified. The public confidence in Wall Street was shaken. Government regulators and Congress began to look for weaknesses in the system. Investors wondered why there was no seemingly no warning of these impending disasters. Although there are tools in place that are meant to provide warning signals of firm financial distress, the reality of the situation is that judging the health of a firm is an uncertain, complex process. Every year, each publicly traded company is required to issue audited financial statements. The effectiveness of the existing audit process was called into question following the spectacular bankruptcies that occurred in 2001 and 2002. During the U.S. Senate deliberations on the bill that would become the Sarbanes-Oxley Act of 2002 (SOX-2002), Weiss submitted a controversial report that suggested that of the 228 public companies that filed for bankruptcy in 2001, Enron and 95 other companies received clean audit opinions. While the Weiss report has been criticized by authors such as Maers, Maher, and Giacomino (2003) for presenting research that does not support the report's conclusions, this controversy highlights the importance of the ongoing discussion on the topic of an auditor's responsibility to assess the going concern status of a company.

This paper evaluates the effects of SOX-2002 in empowering independent auditors to provide unbiased opinions of an entity's ability to remain as a going concern. As firms continue to file for bankruptcy with little warning, community workforces are terminated or reduced, reorganizations continue to create internal havoc, and stockholders face potential stock devaluations and de-listings. When a substantial doubt opinion is warranted, it should contain useful information to provide stakeholders early warning for use in mitigating investment risks with firms that have underlying substantial doubt issues.

This research seeks to determine the accuracy of the auditor's opinion and its probability of signaling bankrupt state migration. The goal of the paper is to determine if auditors are successfully identifying firms with 
substantial doubt that migrate to a bankrupt state in the future. If true, this opinion would provide new information to the investment community and assist in restoring auditor confidence in light of recent corporate misconduct.

Recent events involving allegations of ethical misconduct by corporate executives should motivate the auditing community to provide an unbiased review of financial statements to determine bankruptcy risk. Due to the severity of these corporate scandals, Congress mandated and the President signed into law SOX-2002 to affect sweeping corporate disclosure and financial reporting reform to thwart continued scrupulous activities. This Act was primarily designed to restore investor confidence following well-publicized bankruptcies where independent auditors failed to provide substantial opinions as to the ability of a firm to remain as a going concern. This study reviews the accuracy of the independent auditor opinion (IAO) in signaling bankruptcy and evaluates the effectiveness of the implementation of SOX-2002. Specifically, this study attempts to determine if SOX-2002 has empowered the auditor to give an opinion of substantial doubt that would warn stakeholders of bankruptcy risks greater than chance.

If this research determines that post-SOX-2002 IAOs of substantial doubt signal bankrupt state migration greater than chance occurrence, this could be used in reducing the cost of firm misclassification, which was a concern of Koh (1991). An opinion of substantial doubt is, in essence, an opinion of a high probability of firm cessation. Therefore, it follows that bankruptcy filing, which is a firm's legal cessation of immediate business operations, is often a derivative outcome of such an opinion. Significant proportional differences in success and failure rates of these opinions will help determine if the success rates are greater than chance occurrences of these events. These results can be used to validate the efficiency of the implementation of SOX-2002 with respect to IAOs.

\section{AUDITING STANDARDS BACKGROUND}

Auditor guidance with respect to the analysis of firm annual reports is often generated by Statements on Auditing Standards (SAS) issued by the American Institute of Certified Public Accountants (AICPA). Previous studies evaluating SAS guidelines suggest that factors such as fear of reprisal, litigation, and biased opinions due to improper relationships with management may have minimized the success rate of IAOs. Studies on SAS guidance implementation are mixed in determining if these IAOs have minimized the costs of misclassification where firms that were given going concern opinions later migrated to a bankrupt state.

In 1981, the AICPA issued SAS No. 34: The Auditor's Considerations When Question Arises about an Entity's Continued Existence. In this issue, a going concern opinion was warranted unless observable and quantitative evidence existed contrary to this opinion (Levitan and Knoblett, 1985). Prior to 1981, little guidance was given for documenting cases of substantial doubt when a firm's continued existence was in question until the AICPA issued SAS No. 54. However, even SAS No. 54 was found to be of little economic value due to its meaningless and ambiguous language. This guidance merely suggested that auditors use subjective evaluation methods in issuing their opinions. In 1987, a proposed SAS guideline suggested more serious auditor involvement and opinion accountability but again failed to motivate a more rigorous auditor review. In 1988, this proposal was amended and the AICPA issued SAS No. 59 in an attempt to combat the going concern issue.

Since 1989, SAS No. 59 has provided guidance to the auditor in the conduct of a financial audit to determine a firm's ability to continue as a going concern based on a going concern assumption. When the going concern assumption fails to hold, an opinion of substantial doubt is mandated. The going concern assumption is the continuation of the firm in the absence of significant contrary evidence. Contrary evidence exists when an auditor determines that a firm does not have the ability to meet its continual obligations as they become due without substantial disposition of assets, debt restructuring, externally forced revisions of its operations, or similar activities (SAS NO. 59.01) within one year from the firm's annual report (SAS NO. 59.02). Although, an opinion of doubt may be waived if the auditor believes management has presented a case in which it plans to mitigate the effects of such events (SAS NO. 59.03 and SAS NO. 59.12). SAS No. 59 recognizes that a firm may cease to exist following a going concern opinion and suggests that this opinion should not reflect negatively on the auditor because the opinion only assesses general assurance of a firm's ability to remain as a going concern (SAS NO. 59.04). 


\section{Literature Review}

Some argue that the continued existence of corporate irregularities after the issuance of SAS No. 59 suggests that auditors are not being held accountable. However, auditors are faced with complex situations when assessing the going concern status of a firm. The issuance of a going-concern opinion by an auditor is a serious situation for the affected firm. Koh (1991) found that bankruptcy prediction models can be useful to auditors in making going concern assessments. His work was the first to explicitly consider the misclassification costs of Type I and Type II errors when determining the optimal cut-offs points for the probit model. Misclassification is an extremely important consideration for auditors making going concern assessments. As Tucker, Matsumura, and Subramanyam (2003) suggest, there is a self-fulfilling prophecy effect associated with the issuance of going concern opinions. Specifically, when an auditor publicly expresses doubt in a company's ability to continue as a going concern, it may hasten the company's end. Therefore, auditors must carefully weigh the risks and benefits of issuing a going-concern opinion.

Given the complex nature of the issues surrounding going concern opinions, it is not surprising that several researchers have studied this area. These studies have shown that both qualitative and quantitative factors are important when auditors consider whether or not to issue a going-concern opinion. In fact, SAS No. 59 specifically directs auditors to consider factors beyond the company's current financial position. Koh (1991) suggested that variables such as management ability and future plans, which were introduced by SAS No. 59, could affect the probability of a firm continuing as a going concern. Behn, Kaplan and Krumwiede (2001) find that auditors are sensitive to information provided in publicly disclosed management plans available in $10-\mathrm{K}$ reports, the management discussion and analysis (MD\&A), and annual reports. In particular, they conclude that management plans may mitigate negative financial information that may otherwise lead to a going concern opinion.

Raghunandan and Rama (1995) suggest that SAS No. 59 was issued in response to public concerns about auditors not providing early warnings of client failures. After controlling for financial factors and size, they found that the proportion of client bankruptcies with prior going-concern modified reports was significantly higher after SAS No. 59 became effective than it was prior to the implementation of SAS No. 59. Thus, they suggested that SAS No. 59 had a significant positive effect on the auditor's report of firms in financial distress. They concluded that the efforts of the Accounting Standards Board (ASB) in issuing SAS No. 59, which contained additional guidance to auditors in identifying firms having substantial doubt, were successful.

As a continuation of earlier work, Geiger, Raghunandan, and Rama (1998) studied the mean probability of bankruptcy before and after the implementation of SAS No. 59. They found no significant difference in the mean probability of bankruptcy between the two periods, which indicates that auditors were not issuing going-concern modified reports to differently stressed companies post-SAS 59. Therefore, they suggest that SAS No. 59 only codified existing practice as auditors were actively evaluating the going-concern status of clients prior to SAS No. 59. Taken together, the findings of these two studies (Raghunandan and Rama (1995) and Geiger (1998) et al) suggest that auditor reporting post-SAS No. 59 may have improved because more bankrupt companies are receiving going concern modified reports, yet a similar percentage of companies fail after receiving these reports.

In contrast, Grice (2000) supported Koh's 1991 findings that prior to the issuance of SAS No. 59, auditors were not accountable in their evaluation of a firm's going concern opinion. However, as a result of SAS No. 59, auditors have been required to take a more active role in determining the going concern opinion. However, Grice found that prediction models continued to outperform auditors at signaling impending failure post-SAS No. 59. Essentially, he found that the increased responsibility imposed by SAS No. 59 did not affect the efficiency or accuracy of an auditor's opinion of the going concern issue.

A recent study by Citron and Taffler (2004) suggests that the language required when issuing a going concern opinion may impact the willingness of auditors to issue going-concern opinions. Citron and Taffler (2004) tested the impact of a new audit reporting standard versus an enhanced audit procedures standard in the U.K. They found that the increase in going-concern opinions during the 1990s, a strong economic period in the U.K., was directly associated with the introduction of a less confrontational audit reporting standard. This finding suggests that 
less contentious boilerplate language for going concern reports may encourage more auditors to issue going-concern opinions for financially distressed firms.

In summary, there is a lack of consistent findings in the literature with respect to the information content of IAOs. This research seeks to expand the current body of knowledge by extending Geiger et al (1998) and studying the ability of auditors to successfully identify firms with substantial doubt that migrate to a bankrupt state post-SOX2002. After reviewing the limited success of pre-SOX-2002 SAS guidance and the desired effects of SOX-2002, this research asserts that the latter mandate has empowered the independent auditor to give unbiased opinions of substantial doubt that signal bankrupt state migrations with success rates greater than chance. If true, then a significant economic stakeholder wealth effect can be realized through the warning signals of these opinions.

\section{METHOD}

This study evaluates success rates using three proposed models: a benchmarked Events Model $^{1}$, an Auditor Model, and a Chance Model. The Events Model evaluates the naturally occurring rates of going concern bankrupt state migrations. The Auditor Model evaluates the proportion of firms with IAOs of substantial doubt that migrate to the bankrupt state. The Chance Model evaluates the probability that a going concern selected at $S_{t}$ migrates to a bankrupt state at $\mathrm{S}_{\mathrm{t}+1}$ by chance.

The goal is to determine if significant differences exist in trial successes ${ }^{2}$ of going concerns selected to migrate to a bankrupt state from $\mathrm{S}_{\mathrm{t}}$ to $\mathrm{S}_{\mathrm{t}+1}{ }^{3}$ between the Auditor Model and Chance Model. The binomial $\underline{\mathrm{Z}}$-statistic shown as equation (1) is used to evaluate the proportional success rate differences:

$$
\underline{z}=\frac{\hat{p}_{1}-\hat{p}_{2}}{\sqrt{\frac{\hat{p} \hat{q}}{n_{1}}+\frac{\hat{p} \hat{q}}{n_{2}}}},
$$

where, $\hat{p}_{1}$ is computed as the proportional difference in success rates of the Auditor Model from those of the Events Model, $\hat{p}_{2}$ is computed as the proportional differences in success rates of the Chance Model from those of the of the Events Model, $\hat{p}=\frac{r_{1}+r_{2}}{n_{1}+n_{2}}$ and $\hat{q}=1-\hat{p}$, where $\mathrm{r}_{1}$ and $\mathrm{r}_{2}$ are the number of trail successes of the Auditor and Chance Models, respectively; and $\mathrm{n}_{1}$ and $\mathrm{n}_{2}$ are the sample sizes of Auditor and Chance Model firms, respectively. ${ }^{4}$

\section{Research design}

The AICPA's auditor guidance suggested that a dichotomous classification system be used to indicate an entity's future state as either the continuation or discontinuation of its current status. Therefore, this study evaluates the success rates of these opinions in predicting bankrupt state migrations. ${ }^{5}$ This study is unique in that it evaluates those success rates against a random selection of firms that naturally migrated to bankrupt state during the evaluation period. Previous bankrupt state migration studies (Raghunandan and Rama 1995, Chen and Church 1992, and Levitan and Knoblett 1985) did not rule out these chance effects.

\section{Data collection}

The secondary data for this research were contained in independent auditor statements within 10-K annual reports filed with the Securities and Exchange Commission (SEC). These firms were screened to include those that: (1) trade on a U.S. market exchange, (2) have a U.S. state of incorporation, (3) are located and operating in the U.S., (4) have a non-ADR status, and (5) do not have a SIC 6000 identification (to omit financial institutions). The data were collected iteratively through sequential reviews from the SEC website (www.sec.gov).

The pre-migration period, $\mathrm{S}_{\mathrm{t}}$, is the period of the current $10-\mathrm{K}$ annual report, which was the period prior to the evaluation period. This allows for a 12-month study period for the evaluation period, $\mathrm{S}_{\mathrm{t}+1}$. 
This study benchmarks the actual successes of the Events Model $^{6}$ to determine significant proportional trial differences between the Auditor Model ${ }^{7}$ and the Chance $\mathrm{Model}^{8}$ in correctly signaling bankrupt state migrations. If the Auditor Model is found to have greater trial successes than the Chance Model, then stakeholders can use it as a timely signal of potential financial health problems for a firm so that preemptive measures can be taken to minimize bankruptcy costs.

\section{RESULTS}

The evaluation period was initially developed as the latest time frame available prior to the initiation of this study so current market information could be used. This period was determined to be from October 2003 through September 2004. A sample of 3,883 firms from the 12-month pre-migration period was used to determine Auditor and Chance Model success rates (see Table 1 and Figure 1). (Insert Table 1 and Figure 1 here.) 10-K annual reports from the same time period were reviewed for substantial doubt opinions. These firms were then reviewed in the evaluation period to determine subsequent bankrupt state migrations.

A total of 401 bankrupt and going concern firms from the Events Model were used to evaluate the Chance and Auditor Models. These firms were randomly selected from the 3,883 pre-migration going concerns in proportion to the number of bankrupt firms determined during the evaluation period (see Table 1). The bankrupt firms were going concerns at $S_{t}$ that migrated to a bankrupt state during the evaluation period. The sampling proportions and success rates are summarized below.

The Events Model included 61 bankrupt and 340 healthy firms, which accounted for a 100\% success rates. The Auditor Model and Chance Models each consisted of 68 bankrupt and 333 going concerns, which were selected from the 3,883 pre-migration Events Model going concerns. Of the 68 Chance Model firms randomly selected at $S_{t}$ to migrate to a bankrupt state, 11 migrated to a bankrupt state and 57 remained as going concerns during the evaluation period, which was a $16.18 \%$ success rate. Of the 68 Auditor Model firms classified as having substantial doubt at $\mathrm{S}_{\mathrm{t}}, 27$ migrated to a bankrupt state and 41 firms remained as going concerns during the evaluation period, which was a $39.71 \%$ success rate.

Analysis using a z-statistic also suggests that the Auditor Model has greater trial successes in identifying firms that have the potential to migrate to a bankrupt state $(z=-2.8112) .{ }^{9}$ Therefore, this research suggests that the probability of Auditor Model firms evaluated as having substantial doubt at $S_{t}$ that migrate to a bankrupt state at $S_{t+1}$ is greater than the probability that Chance Model firms selected as bankrupt at $S_{t}$ will migrate to a bankrupt state at $\mathrm{S}_{\mathrm{t}+1}$.

\section{DISCUSSION}

Since differences exist between the Chance and Auditor Models, this study concludes that the Auditor Model contains significant information to use in evaluating the potential for bankrupt state migrations for firms with substantial doubt opinions. As statistically determined, the proportion of success rates of the Auditor Model firms classified at $S_{t}$ with substantial doubt that actually migrated to a bankrupt state during the evaluation period is greater than the rates of the Chance Model bankrupt firms selected and evaluated during this same time period. The implication is that the implementation of the SOX-2002 legislation is empowering the independent auditor's and allowing unbiased opinions of the future state of a firm's existence.

These findings suggest that substantial doubt opinions are more likely than arbitrary selection to identify bankrupt state migrations. Thus, there is now empirical evidence to support continued empirical evaluation of this research question. The ultimate goal is to further assist the auditor in efficiently evaluating the probability of the continued existence of a firm. 


\section{CONCLUSIONS}

This paper investigates the effect of SOX-2002 in empowering the independent auditor to provide an unbiased opinion of an entity's ability to remain as a going concern. The goal was to determine if independent auditor opinions (Auditor Model) provide information that helps to predict bankruptcy state migrations better than a Chance Model. In other words, this investigation helps to determine if auditor opinions are efficient in identifying firms with substantial doubt as to their status as going concerns. If efficiency exists, it would provide important information to the investment community and assist in restoring confidence in the auditor community and in the U.S. financial markets. The underlying issue is the enormous cost of misclassification due to recent events involving allegations of ethical misconduct by corporate executives where no warnings were given to the stakeholder prior to respective bankrupt state migrations. Given these events, oversight neglect of the auditing system has motivated the legislation of SOX-2002 to minimize the effects of continued corporate malfeasance.

This study, which reviews the effectiveness of the IAO in signaling bankruptcy, concludes that the implementation of SOX-2002 is helping to restore the legitimacy of the independent auditor's opinion of substantial doubt in signaling bankruptcy with firms whose continued existence as an entity is in question. While previous studies suggest mixed results, this study concludes that the AICPA SAS No. 59, which is supported by SOX-2002, is an effective tool in signaling bankruptcy migration.

\section{SUGGESTIONS FOR FUTURE RESEARCH}

Future research using the IAO combined with other nominal variables such as default status, debt covenants and other variables that may contribute to the IAO, could be used to fit a statistically significant model to assist the auditor in his/her classification of a firm with respect to the question of substantial doubt. Table 2 lists the 27 bankrupt firms that auditors correctly classified as having substantial doubt in this study. (Insert Table 2 here.) An investigation of these firm's annual reports could provide insights as to the financial and economic causes of bankruptcy migration. LaSalle and Anandaragan (1996) have suggested that an entity's bad news characteristics are more important than those presented by good news. Chen and Church (1992) have suggested that auditors carefully consider default status in making going-concern decisions. They found that a going concern model that includes default status and financial variables outperforms other models in power and in expected cost of misclassification. They also found that auditors rely heavily on default status in making going concern opinions without careful consideration of a firm's financial variables. They suggested that auditors may benefit from the use of a going concern model that includes both default status and financial variables.

In addition, Levitan and Knoblett (1985) found that auditors were successful in predicting going concern difficulties and their opinions were consistent with their client's subsequent health. However, these high success rates were due to auditor tendency not to render a going concern exception, i.e., firms with going concern difficulties were given a going concern opinion even though they found negative information that previously led to a bankrupt status. Chen and Wei (1993) found that debt covenant waiver decisions were more likely to occur with firms with a lower probability of bankruptcy and lower leverage ratio.

\section{REFERENCES}

1. American Institute of Certified Public Accountants, The Auditor's Consideration When a Question Arises About an Entity's Continued Existence, Statement on Auditing Standards No. \# 34, (March), New York: AICPA, 1981.

2. __ Analytical Procedures, Statement on Auditing Standards No. \# 56, (April), New York: AICPA, 1988a.

3. The Auditor's Consideration of an Entity's Ability to Continue as a Going Concern, Statement on Auditing Standards No. \# 59, (April), New York: AICPA, 1988b.

4. Behn, B. K., Kaplan S. E., and Krumwiede, K. R., Further Evidence on the Auditor's Going-Concern Report: The Influence of Management Plans, Auditing, Vol. 20, No. 1, pp. 13-29, 2001.

5. Chen, K. C. W. and Church, B. K., Default on Debt Obligations and the Issuance of Going Concern Opinions, Auditing: A Journal of Practice and Theory (Fall): 30-49, 1992. 
6. Chen, C. W., and Wei, K. C., Creditors' Decisions to Waive Violations of Accounting-Based Debt Covenants, The Accounting Review (April): 218-232, 1993.

7. Citron, D. B. and Taffler, R. J., The Comparative Impact of an Audit Report Standard and an Audit GoingConcern Standard on Going-Concern Disclosure Rates, Auditing: A Journal of Practice \& Theory, Vol. 23, No. 2 (September): 119-130, 2004.

8. Geiger, M. A., Raghunandan K., and Rama, D.V., Going-Concern Audit Report Recipients Before and After SAS No. 59, National Public Accountant, Vol. 43, No. 8, p. 24-26, 1998.

9. Grice, Stephen J., Bankruptcy Prediction Models and Going Concern Audit Opinion Before and After SAS No. 59, Business Quest (January), 2000.

10. Koh, Hian, C., Model Predictions and Auditor Assessments of Going Concern Status, Accounting and Business Research 21: 331-338, 1991.

11. LaSalle, R.E. and Anandaragan, A., Auditor's Views on the Type of Audit Report Issued to Entities with Going Concern Uncertainties, Accounting Horizons (June): 51-72, 1996.

12. Levitan, A. S., and Knoblett, J. A., Indicators of Exceptions to the Going Concern Assumption, Auditing: A Journal of Practice and Theory (Fall): 26-39, 1985.

13. Maers, M.D., Maher, M.A., and Giacomino, D. E., Going-Concern Opinions: Broadening the Expectations Gap, CPA Journal Vol. 73, No. 10 (October): 38-43, 2003.

14. Raghunandan, K. and Rama, D. V., Audit Reports for Companies in Financial Distress: Before and After SAS No. \# 59, Auditing: A Journal of Practice and Theory (Spring): 50-63, 2005.

15. Sarbanes-Oxley Act of 2002, PL107-204, 116 Stat 745, 2005.

16. U.S Securities and Exchange Commission, Edgar Company Search, Retreived from www.sec.gov/edgar/searchedgar /companysearch.html, 2005.

17. Tucker, R. R., Matsumura, E. M. and Subramanyam, K. M., Going-Concern Judgments: An Experimental Test of the Self-Fulfilling Prophecy and Forecast Accuracy, Journal of Accounting and Public Policy (22): pages 401432, 2003.

18. Weiss, M.D., The Worsening Crisis on Wall Street of Confidence on Wall Street: The Role of Accounting Firms, Weiss Ratings, Inc, Available from www.weissratings.com, 2002.

\section{NOTES}

${ }^{1}$ The success rates of Events Model firms benchmarked those of the Auditor and Chance Models.

${ }^{2}$ Trial success occurs either when an auditor correctly classifies a going concern as having substantial doubt at $S_{t}$ and the firm migrates to a bankrupt state at $S_{t+1}$, when a firm was selected at $S_{t}$ from the Chance Model to migrate from $S_{t}$ to a bankrupt state at $S_{t+1}$, or when firms migrated to a bankrupt state naturally, as with Event Model firms. The intent is to determine which model has the maximum correct trial successes of bankrupt state migrations.

${ }^{3} \mathrm{~S}_{\mathrm{t}}$ is the period of the $10-\mathrm{K}$ annual report and $\mathrm{S}_{\mathrm{t}+1}$ is the post $10-\mathrm{K}$ annual report period or evaluation period.

${ }^{4}$ This is a left-tailed test because of the interest in evaluating the differences in the success rates of the Auditor and Chance Models as compared o the Events Model $(\alpha=.01$ and C.V. $=-2.33)$. This is justified due to the high cost of misclassification of unforecasted bankrupt state migrations.

${ }^{5}$ A classification of substantial doubt means that a firm may not remain as a going concern. The legal way of migrating to this state is through insolvency proceedings or bankruptcy. Given this cost as a major economic and financial concern (Koh, 1991) and the attempt of SOX-2002 to make corporate executives accountable, it was a natural progression to evaluate the success rates of these substantial doubt opinions.

${ }^{6}$ This evaluated going concern bankrupt state migrations from $S_{t}$ to $S_{t+1}$.

${ }^{7}$ This evaluated firm's with substantial doubt opinions bankrupt state migration from $S_{t}$ to $S_{t+1}$.

${ }^{8}$ This evaluated the chance occurrences of going concerns selected at $S_{t}$ to migrate to a bankrupt state at $S_{t+1}$.

${ }^{9}$ The raw data for the $z$ calculation is, $z=\frac{\left(\frac{100}{100}-\frac{27}{68}\right)-\left(\frac{100}{100}-\frac{11}{68}\right)}{\sqrt{\frac{(.31)(.69)}{61}+\frac{(.31)(.69)}{61}}}=-2.8112$. 
Table 1: Proportional Bankrupt-Healthy Sample

\begin{tabular}{|l|c|c|c|c|c|c|}
\hline & \#BR & \#H & $\mathbf{P}(\mathbf{B R})$ & $\mathbf{P}(\mathbf{H})$ & \#H*(P(BR)) & Rounded \\
\hline Oct-03 & 8 & 103 & 0.13 & 0.03 & 13.51 & 14 \\
\hline Nov-03 & 5 & 43 & 0.08 & 0.01 & 3.52 & 4 \\
\hline Dec-03 & 5 & 2866 & 0.08 & 0.74 & 234.92 & 235 \\
\hline Jan-04 & 7 & 175 & 0.11 & 0.05 & 20.08 & 20 \\
\hline Feb-04 & 7 & 57 & 0.11 & 0.01 & 6.54 & 7 \\
\hline Mar-04 & 7 & 219 & 0.11 & 0.06 & 25.13 & 25 \\
\hline Apr-04 & 3 & 67 & 0.05 & 0.02 & 3.30 & 3 \\
\hline May-04 & 5 & 71 & 0.08 & 0.02 & 5.82 & 6 \\
\hline Jun-04 & 6 & 232 & 0.10 & 0.06 & 22.82 & 23 \\
\hline Jul-04 & 2 & 35 & 0.03 & 0.01 & 1.15 & 1 \\
\hline Aug-04 & 3 & 10 & 0.05 & 0.00 & 0.49 & $1 *$ \\
\hline Sep-04 & 3 & 5 & 0.05 & 0.00 & 0.25 & $1 *$ \\
\hline Total & 61 & 3883 & 1.00 & 1.00 & 338 & 340 \\
\hline
\end{tabular}

*Notes: This table reports the results of the methodology in determining the proportional sample of bankrupt and healthy firms at $\mathrm{S}_{\mathrm{t+1}}$. This proportion consists of a base of 61 firms that migrated to a bankrupt state and a proportional sample of 340 healthy firms. The basis of this sample was 3,883 firms selected by fiscal year in proportion to the bankrupt firms across number and fiscal year from October 2003 through November 2004. For example, in Oct-03, there were 8 bankrupt firms (\#BR) and 103 healthy firms $(\# H)$. The proportion of bankrupt firms $(\mathrm{P}(\mathrm{BR}))$ was $0.13(8 / 61)$ and healthy firms $(\mathrm{P}(\mathrm{H}))$ was $0.03(103 / 3883)$. This following that the proportion of firms in Oct-03 was $13.51(\# \mathrm{H} *(\mathrm{P}(\mathrm{BR}))$, which was rounded to 14.

Table 2: Correctly Identified Firms Classified as Having Substantial Doubt that Actually Migrated to a Bankrupt State at $S_{t+1}$.

\begin{tabular}{|c|c|c|c|c|c|}
\hline Name & SIC & CIK & $\begin{array}{c}\text { Bankruptcy } \\
\text { Date }\end{array}$ & CPOR & FAOD \\
\hline Acclaim Entertainment, Inc. & 7372 & 804888 & $9 / 1 / 2004$ & 20040331 & 20040701 \\
\hline Avado Brands & 5812 & 849101 & $2 / 4 / 2004$ & 20021229 & 20030304 \\
\hline Big Buck Brewery \&Steakhouse, Inc. & 5810 & 1009652 & $6 / 10 / 2004$ & 20021229 & 20040223 \\
\hline Briazz, Inc. & 5812 & 1045598 & $6 / 7 / 2004$ & 20031228 & 20040330 \\
\hline Dexterity Surgical & 3842 & 860131 & $3 / 19 / 2004$ & 20031231 & 20040329 \\
\hline Driver Harris Co. & 3350 & 30197 & $11 / 26 / 2003$ & 20021231 & 20030509 \\
\hline DT Industries & 3559 & 918999 & $5 / 12 / 2004$ & 20030629 & 20031014 \\
\hline Eagle Building Tech. Inc. & 3270 & 947431 & $1 / 30 / 2004$ & 20021231 & 20030728 \\
\hline Entertainment Technologies \& Programs, Inc. & 7900 & 922257 & $11 / 6 / 2003$ & 20020930 & 20030116 \\
\hline Fortune Natural Resources Corp. & 1311 & 38242 & $6 / 1 / 2004$ & 20011231 & 20020412 \\
\hline Holiday RV Superstores, Inc. & 5500 & 822076 & $10 / 20 / 2003$ & 20021231 & 20030603 \\
\hline International Biochemical Industries, Inc. & 2842 & 1059623 & $1 / 17 / 2004$ & 20020630 & 20021016 \\
\hline Minorplanet Systems USA & 4812 & 944400 & $2 / 2 / 2004$ & 20030831 & 20031201 \\
\hline MPM Technologies & 1040 & 799268 & $3 / 19 / 2004$ & 20031231 & 20040415 \\
\hline One Price Clothing Stores & 5621 & 812446 & $2 / 9 / 2004$ & 20030201 & 20030523 \\
\hline Online Power Supply, Inc. & 4911 & 1101152 & $5 / 14 / 2004$ & 20011231 & 20020415 \\
\hline Options Talent Group & 7310 & 741012 & $10 / 31 / 2003$ & 20020731 & 20021113 \\
\hline Prologic Management Systems & 5045 & 938320 & $2 / 2 / 2004$ & 20030331 & 20030630 \\
\hline RCN Corp. & 4813 & 1041858 & $5 / 27 / 2004$ & 20031231 & 20040429 \\
\hline Redline Performance Products, Inc. & 3790 & 1121131 & $8 / 27 / 2004$ & 20040331 & 20040331 \\
\hline Reptron Electronics, Inc. & 5065 & 918765 & $10 / 28 / 2003$ & 20021231 & 20030415 \\
\hline Republic Engineered Products Holdings LLC & 3312 & 1216462 & $10 / 6 / 2003$ & 20021231 & 20021231 \\
\hline Rouge Industries, Inc. & 3312 & 918577 & $10 / 23 / 2003$ & 20021231 & 20030218 \\
\hline U.S. Plastic Lumber Corp. & 4955 & 1014851 & $7 / 23 / 2004$ & 20021231 & 20030415 \\
\hline Universal Access Global Holdings, Inc. & 4812 & 1070699 & $8 / 4 / 2004$ & 20031231 & 20031231 \\
\hline Wickes, Inc & 5211 & 910620 & $1 / 20 / 2004$ & 20021228 & 20030411 \\
\hline Women First Healthcare, Inc. & 5122 & 1081004 & $4 / 29 / 2004$ & 20031231 & 20040330 \\
\hline
\end{tabular}


Figure 1: Events Model, Chance Model, and Auditor Model Classification Results

\begin{tabular}{|c|c|c|c|c|c|c|c|c|c|}
\hline & & & & \multirow{11}{*}{ 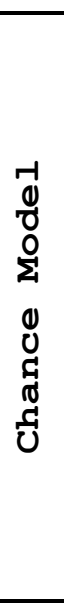 } & \multirow[b]{4}{*}{401} & \multirow[b]{2}{*}{68} & 11 & $16.18 \%$ & Success Rates \\
\hline & & & & & & & $\mathrm{BR}$ & & \\
\hline & & & & & & \multirow[t]{2}{*}{ BR } & 57 & $83.82 \%$ & Error Rates \\
\hline & & & & & & & $\mathrm{H}$ & $100.00 \%$ & \\
\hline & & & & & \multirow[t]{5}{*}{ Total } & & & & \\
\hline & & & & & & & 41 & $12.31 \%$ & \\
\hline & & & & & & 333 & $\mathrm{BR}$ & & \\
\hline & & & & & & $\mathrm{H}$ & 292 & $87.69 \%$ & \\
\hline & & & & & & & $\mathrm{H}$ & $100.00 \%$ & \\
\hline \multirow{6}{*}{ 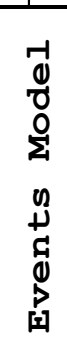 } & \multirow{2}{*}{\multicolumn{3}{|c|}{$\begin{array}{c}\text { Success } \\
\text { Rates }\end{array}$}} & & 401 & 401 & 401 & & \\
\hline & & & & & St & St & $S t+1$ & & \\
\hline & \multicolumn{2}{|r|}{61} & BR $100.00 \%$ & & & & & & \\
\hline & 401 & $\mathrm{BR}$ & & & & & & & \\
\hline & & 340 & H $100.00 \%$ & \multirow{11}{*}{$\begin{array}{l}-1 \\
0 \\
0 \\
0 \\
\Sigma \\
H \\
0 \\
+ \\
-1 \\
0 \\
J \\
J\end{array}$} & \multirow[b]{4}{*}{401} & \multirow[b]{2}{*}{68} & 27 & $39.71 \%$ & Success Rates \\
\hline & & $\mathrm{H}$ & & & & & $\mathrm{BR}$ & & \\
\hline & & & & & & \multirow[t]{2}{*}{ SD } & 41 & $60.29 \%$ & Error Rates \\
\hline & & & & & & & $\mathrm{CG}$ & $100.00 \%$ & \\
\hline & & & & & \multirow[t]{3}{*}{ Total } & \multirow[b]{3}{*}{333} & & & \\
\hline & & & & & & & 34 & $10.21 \%$ & \\
\hline & & & & & & & BR & & \\
\hline & & & & & & \multirow[t]{2}{*}{ CG } & 299 & $89.79 \%$ & \\
\hline & & & & & & & $\mathrm{CG}$ & $100.00 \%$ & \\
\hline & & & & & 401 & 401 & 401 & & \\
\hline & & & & & St & St & $\mathrm{St}+1$ & & \\
\hline
\end{tabular}

Notes:

1. The Events Model consisted of a total of 401 firms selected from a sample of 3,883 firms. Of these, 61 went bankrupt (BR) during the evaluation period and 340 remained as going concerns (GC). The success rates were simply the actual number of BR state migrations of the BR firms and the actual number of firms that remained as GCs during the evaluation period.

2. The Chance Model firms were sampled from the 401 Events Model firms. Of these firms, 68 were selected to migrate to a BR state and 333 were selected to remain as GCs. This yielded a $16.18 \%$ success rate and an $83.82 \%$ failure rate.

3. The Auditor Model firms were sampled from the 401 Events Model firms. These firms consisted of the same initial proportion of firms selected to migrate to a BR state and to remain as GCs (68 and 333 respectively). This yielded a $39.71 \%$ success rate and an $60.29 \%$ failure rate. 


\section{NOTES}

